emphasized by the author of the present volume, which endeavours to present a view suitable for the engineer to use in the designing of structures.

Such a complex subject inevitably involves some major assumptions, acceptable to the designer but not necessarily to the scientist concerned with deformation mechanisms. The mathematical theory builds up to cover beams, membranes, plates, shells and thick-walled tubes. Relaxation is dealt with very briefly, although the jacket claims it as one subject receiving "special attention". A table of creep constants of typical structural metals is admitted to be incomplete, but at least some thermal history of specific steels is given-a rare concession in tables of this kind. A short chapter on dislocations, preceding the main theory, is rather superfluous, and makes curious reference to "arbitrary assumptions" as if all the mathematical theory presented by the author were untarnished. Nevertheless, problems of stability and exercises in the proper utilization of creep testing data are distinct contributions to knowledge in high temperature applications and are presented with great clarity. Mechanical, chemical, aeronautical and "space" engineers will benefit most from this book.

C. R. TOTTLE

\section{FERROUS ALLOYS}

The Technology and Properties of Ferrous Alloys for High-Temperature Use

By M. G. Gommill. (Newnes International Monographs on Materials Science and Technology.) Pp. xii +242. (London: George Newnes, Ltd., 1966.) 70s. net.

'THIs monograph begins a series aiming to cover various aspects of materials science and technology in relation to the needs of engineering design and construction. High temperature steels serve well in this context to illustrate important problems and principles in developing alloys and producing components in a field of stringent service conditions. In this field the author hopes to give "both engineers and metallurgists greater insight into one another's problems", and the theme that their activities are complementary and should be co-ordinated is brought out by the treatment adopted.

Metallurgical matters are mostly dealt with in some detail and depth, and this necessitates the assumption that the reader is familiar with certain basic topics such as the constitution and structures of plain carbon steels. The first chapter outlines some aspects of dislocation theory, however, before briefly reviewing theories of high temperaturo mechanical properties.

The second chapter gives a broad and critical treatment of relovant testing procedures. There follow four chapters on the relation of constitution and structure to high temperature properties of carbon steels, ferritic steels, and simple and complex austenitic steels. Aspects of corrosion resistance and welding are effectively covered in separate chapters. The final chapter, "Mechanical Properties and High Temperature Engineering", deals with design stressing and with the use of high temperature steels in land power plant, gas turbines and the petrochemical industry.

The book is well illustrated, both with respect to test result data and microstructures, and it includes chapter summaries and substantial lists of references. An interesting feature is that it deals with the technological approach of various countries in this field. There are a few misprints or phrases to be querried-for example, some of the definitions in Table 1 require critical attention.

The book should be of interest and value to final-year degree students in metallurgy, materials science and mechanical engineering as well as to practising metallurgists and engineers.

\section{NUCLEAR ENERGY LAW}

\section{Law Relating to Nuclear Energy}

By Harry Street and F. R. Frame. Pp. xviii +320. (London: Butterworth and Co. (Publishers), Ltd., 1966.) $110 s$. net.

A воок on the law relating to nuclear energy is timely, and no more suitable author could have been found than Professor Street, with his wide knowledge of the law of tort and particularly of the problem of liability. The book is excellently organized. It begins with a description of the roles of all the organizations in the United Kingdom dealing with atomic energy-government departments, the United Kingdom Atomic Energy Authority, the Central Electricity Generating Board, the South of Scotland Electricity Board and private industry. It passes on to deal with the licensing of nuclear installations, the question of civil liability both before and after the Nuclear Installations Act, 1965, and the detailed rules about the use and transport of radioactive materials. At this stage it becomes necessary to consider international regulations, and the book deals comprehensively with the activities of the International Atomic Energy Agency, the European Nuclear Energy Agency, the European Atomic Energy Community and the European Organization for Nuclear Research. Liability arising from the operation of nuclear installations outside the United Kingdom is then discussed, as are the special problems of nuclear ships and patents. The texts of the principal United Kingdom statutes and international conventions concerned with questions of nuclear energy are given in one appendix and a glossary of atomic terms in another.

To produco as comprehensive and lucid an exposition of so difficult a subject in just over three hundred pages is a remarkable achievement on which the authors are to be warmly congratulated.

D. H. N. JoHNSON

\section{CANE SUGAR TECHNOLOGY}

\section{Introduction to Cane Sugar Technology}

By G. H. Jenkins. Pp. xvii + 478. (Amsterdam, London and New York: Elsevier Publishing Company, 1966.) $115 s$.

THIs book, originally intended as a text-book for postgraduate studonts, is written in such a comprehensive and informative way that it is certain also to be welcomed by many practising engineers, chemists and technologists in the sugar industry. The usual mistake of trying to cover a wide technological subject in too much detail has been wisely avoided, and the result is a text which is highly readable and relatively easy to follow, even without previous specialized knowledge. The volume is up to date and contains a certain amount of information from Australian sources, hitherto unpublished or scattered in publications not readily available. Recommendations for further reading lead inevitably to P. Honig, G. P. Meado and E. Hugot, from whose standard works on sugar technology the author frequently quotes.

The book deals competently with all important aspects of cane sugar production-cane preparation, feeding, imbibition, crushing, juice extraction, defecation, clarification, evaporation, sugar boiling, centrifuging, drying and storing. Mill capacity and power, most significant items in mill economy, are discussed critically. The difficulty of obtaining reliable data for friction coefficient and friction load, major components of total power requiroments, is duly emphasized. When discussing the chemistry of defecation and clarification, the author quite rightly makes the point that $3-5$ per cent of the soluble cane juice solids consists of still unidentified nonsugars which may include some with a profound effect on the mechanism of the process. The principles and practice of sugar boiling, as distinct from crystallization, 